\title{
Ectopic Adrenocortical Tissue Attached to the Inguinal Sac in an Adult
}

\author{
Yurdacan $\mathrm{M}^{1 *}$, Turgut $\mathrm{BC}^{1}$, Akıncı $\mathrm{O}^{2}$, Uner $\mathrm{MB}^{3}$ \\ and Ergun $\mathrm{S}^{1}$ \\ ${ }^{1}$ Department of General Surgery, Istanbul University- \\ Cerrahpasa, Turkey \\ ${ }^{2}$ Department of General Surgery, Kartal Dr. Lutfi Kırdar \\ City Hospital, Turkey \\ ${ }^{3}$ Department of Pathology, Hacettepe University, Turkey \\ *Corresponding author: Yurdacan M, Department of \\ General Surgery, Istanbul University-Cerrahpasa, Turkey
}

Received: December 18, 2020; Accepted: February 02, 2021; Published: February 09, 2021

\section{Introduction}

In 1740, Morgagni first described ectopic adrenal tissue as yellowish nodule in the vicinity of the main adrenal gland [1]. Ectopic adrenal tissue is mostly encountered in children and adolescents. Some authors state that aberrant adrenal tissues may be existing in $50 \%$ of newborns $[2,3]$. The incidence of adrenal tissue in the spermatic cord is less than $1 \%$ in adults $[4,5]$. The low rate is thought to be due to atrophy of ectopic tissue in advanced ages. Ectopic adrenal tissue was reported in various parts of the body such as kidney, coeliac area, thorax, liver, brain [6]. In this article, we present a case of ectopic adrenal tissue in inguinal hernia sac, which is rarely seen in adults.

\section{Case Presentation}

A 28-year-old male patient presented with a complaint of swelling and pain in the right groin that he noticed 6 months ago. On physical examination, it was observed that the swelling was compatible with the right indirect inguinal hernia and could be reduced. Testicle was normal on palpation. There was no history of previous surgery or diagnosis with undescended testicle. His routine laboratory tests were normal. Lichteinstein repair of inguinal hernia was performed on the patient. An orange-yellowish nodular tissue of different color and consistency was observed in the vicinity of the indirect hernia sac. It was excised for pathological examination.

In the pathological examination, the specimen contained cream-yellow soft tissues with a size of $3.5 \times 2 \times 2 \mathrm{~cm}$ macroscopically. Microscopic examination revealed that this orange nodule was compatible with an ectopic adrenal tissue (Figure 1). The adrenal gland cells in the sections were largely belonging to the zona fasciculate and zona reticularis which are the parts of the cortex. No increased mitosis, pleomorphism or necrosis suggesting a neoplastic process was observed. During postoperative follow-up, the patient had no imbalance in adrenal hormones in laboratory.

\section{Discussion}

Embryologically the adrenal gland origins from two primordia The fetal adrenal cortex is derived from the mesoderm and the medulla arises from the ectoderm [2-4]. It is generally accepted that adrenal remnants result from the displacement and separation of cortex during the migration and descent of the gonads during the embryonic period. While some adrenal heterotopic tissues remain near the kidney, some may migrate as the gonads descend into the pelvis and scrotum [3]. The tissues that located near to the original position may comprise medulla but the distant ones may generally contain cortex $[2,3]$. Ketata et al., found ectopic adrenal tissue in $1.66 \%(n=31)$ of 1862 patients who underwent inguinoscrotal surgery, and none of them had an adrenal medulla [7]. However, Oguz et al., in 1 of 6 patients, they found the adrenal cortex and adrenal medulla together within the ectopic tissue [6].

The pathological appearance of this ectopic tissue in the inguinal canal is characteristic. Findings show a yellowish round nodule of 1-5 $\mathrm{mm}$ in diameter within cremasteric fibers [3-5,7]. The question of whether we should remove these nodules is important. Although ectopic adrenal tissues are not usually related with endocrine abnormalities, they can cause conditions such as hyperplasia and malignancy in some cases. Some authors reported that ectopic tissues showed compensatory hypertrophy in patients who underwent total adrenalectomy. In addition, it has been observed that various surgical interventions on these ectopic tissues cause adrenal insufficiency. Another clinical feature is the transformation to malignancy from ectopic adrenal remnants. It has been reported that
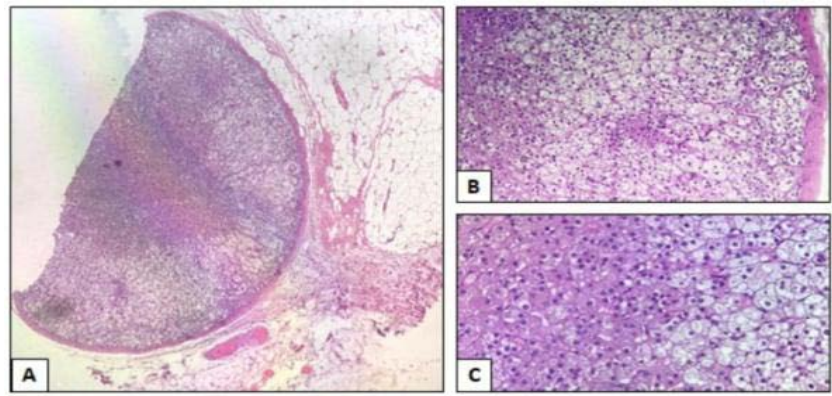

Figure 1: A: Ectopic adrenal tissue surrounded by a thiny fibrous capsule (H\&E; 4X). B-C: The cells that constitute the adrenal tissue; from right to left, the cells of zonae glomerulosa, fasciculata and reticularis (H\&E; 10X and 20X).
Austin J Surg - Volume 8 Issue 1 - 2021

ISSN : 2381-9030 | www.austinpublishing group.com

Yurdacan et al. (C) All rights are reserved
Citation: Yurdacan M, Turgut BC, Akıncı O, Uner MB and Ergun S. Ectopic Adrenocortical Tissue Attached to the Inguinal Sac in an Adult. Austin J Surg. 2021; 8(1): 1261 
pheochromocytoma, Leydig cell tumors and adrenal adenomas can very rarely develop from these ectopic tissues [1-6].

\section{Conclusion}

Ectopic adrenal tissue is a rare condition encountered in inguinal hernia surgery. For surgeons, the possibility of ectopic adrenal tissue should be kept in mind when encountering yellow-orange nodular structures around the inguinal hernia sac. Considering the hormone production and malignant transformation of this nodule, excision and histological examination is recommended.

\section{References}

1. Schechter DC. Aberrant Adrenal. Ann Surg. 1968; 167: 421-426.

2. Anderson JR, Ross AH. Ectopic adrenal tissue in adults. Postgr Med J. 1980; 56: 806-808.
3. Mendez R, Tellado MG, Somoza I, Liras J, Vela D. Ectopic Adrenal Tissue in the Spermatic Cord in Pediatric Patients : Surgical Implications. Int Braz J Urol. 2006; 32: 202-207.

4. Takeuchi M, Okuya K, Kato R, Miyao N, Konishi Y. Aberrant Adrenocortical Tissue Associated with Resected Lipoma of Spermatic Cord in an Adult. Open J Urol. 2014; 4: 151-154.

5. Floyd MS, Itam S, Nasir N, Weerasinghe SM, Irwin PP. Case report Concomitant testicular seminoma and ectopic adrenal tissue of the cord in a 45-year-old male. Can Urol Assoc J. 2014; 8: E176-E178.

6. Oguz F, Yildiz T, Beytur A, Soylemez H, Altintas R, Samdanci E, et al. Evaluation of children with inguinoscrotal ectopic adrenal tissues. Turk J Med Sci. 2013; 43: 553-556

7. Ketata S, Ketata H, Sahnoun A, FakhFakh H, Bahloul A, Mhiri MN. Ectopic adrenal cortex tissue: an incidental finding during inguinoscrotal operations in pediatric patients. Urol Int. 2008; 81: 316-319. 